\title{
Fever of Undetermined Origin in Elderly Patients: Causes and Clinical Characteristics
}

\author{
Tarik I. Zaher, Hala I.M Hussein, Noha E. Shahin, Ehab M. Darwish, \\ Mohammed M. Kamal \\ Department of Tropical Medicine, Faculty of Medicine, Zagazig University,Egypt
}

Corresponding Author

Tarik I. Zaher

Mobile:

$+00201001855393$

E mail: tareqzaher@gmail.co $m$

Key words: fever, unknown origin, elderly
Background and study aim: Fever of Undetermined Origin (FUO) continues to be a diagnostic challenge particularly in elderly patients. Reporting local experience is important in guiding clinicians about the epidemiologic pattern in different region. This study aimed to determine causes, clinical presentations and the laboratory findings of FUO among elderly persons $\geq 65$ years in comparison with younger patients.

Patients and Methods: This study was conducted on 54 patients during one year duration from the period between January 2015 and January 2016. Patients were divided into two equal groups of 27 patients who were suffering from FUO. The first one (G1) consisted of elderly patients $\geq 65$ years and the second group

\section{INTRODUCTION}

In 1961, Petersdorf and Beeson introduced the definition of fever of undetermined origin (FUO) that subsequently became standard-namely, fever of more than 3-weeks duration, fever higher than $38.3^{\circ} \mathrm{C}$ on several occasions, and diagnosis uncertain after 1 week of study in hospital [1].

Because hospital admission is so expensive and thorough diagnostic testing now can be performed in outpatient settings, the definition of classic FUO was modified to remove the requirement that a hospital be the setting for 1 week of evaluation. The revised criteria require an evaluation of at least 3 days in the hospital, three outpatient visits, or 1 week of logical and intensive outpatient testing without determining the fever's cause [2].

Durack and Street have proposed a new system for classification of FUO:
(G2) consisted of patients younger than the age of 65 . All patients in this study were subjected to complete history taking adequate physical examinations in addition to routine laboratory investigations and specific investigations (according to case).

Conclusion: Urinary tract infection, chronic calcular cholecystitis and malignancy are important causes for FUO in elderly patients followed by miscellaneous causes as post chemotherapy and drug fever. Non-elderly group showed statistical significant increase in typhoid fever, HIV infection, infective endocarditis, intraabdominal abscess and auto immune disorders when compared to elderly group.

1. classic FUO, 2. nosocomial FUO, 3. Immune deficient FUO, and 4. FUO associated with HIV infection [3].

Febricity in the elderly can be defined as temperature exceeding $37.2^{\circ} \mathrm{c}$ taken orally or of ear drum, or higher than $37.5^{\circ} \mathrm{c}$ taken rectally [4].

The diagnostics of FUO in the elderly often differs from the young patients; the manifestation of a disease is often nonspecific in older patients. The physiologic reserves are diminished in the elderly as well as their immunity. In the elderly many other accompanying diseases may affect the diagnosis, treatment, and the outcome of the illness. The symptoms and signs of many illnesses are atypical or less prominent in older patients, which obviously complicate diagnosis. Thus for instance, cognitive function disorders can be the only sign of infection in the elderly [5]. 
This study aimed to determine causes, clinical presentations and the laboratory findings of FUO among elderly persons $\geq 65$ years in comparison with younger patients.

\section{PATIENTS AND METHODS}

This cohort study was conducted on 54 patients admitted to El- Mehalla Fever Hospital, Tanta Fever Hospital and Zagazig University Hospitals during one year duration from the period between January 2015 and January 2016. Patients with FUO of any type with consideration of temperature $>37.2^{\circ} \mathrm{C}$ orally or $>37.5^{\circ} \mathrm{C}$ per rectum for elderly patients $\geq 65$ years and $>38.3^{\circ} \mathrm{C}$ orally for younger patients were included.

Patients were divided into two equal groups of 27 patients who were suffering from FUO. The first one (G1) consisted of elderly patients $\geq 65$ years and the second group (G2) consisted of patients younger than the age of 65 .

After ethical approval of the study, an informed consent was taken from all patients. All cases were followed up in hospital setting.

All patients were subjected to :

\section{Full history taking:}

Including: age, sex, residence, occupation, travelling abroad, exposure to animals or vectors, drug history, family history, sexual history, history of special habits, the magnitude of the temperature readings and the patterns of fever.

An adequate physical examinations (general and local) including: vital signs, fever chart, head and neck, extremities, musculoskeletal, lymph nodes, dermatological, cardiac, chest, abdominal and full neurological examinations.

\section{Investigations:}

\section{Routine Investigations:}

a. Urine analysis [6].

b. Complete blood count (HB \% - W.B.Cs with differential - platelet count) [7].

c. Liver enzymes tests including ALT, AST [8].

d. Serum urea and creatinine [9]. e. Acute phase reactants: erythrocyte sedimentation rate (ESR), C-reactive protein (CRP) [10].

f. Chest X-ray

g. Pelvi-Abdominal ultrasonography: With special emphasis on liver, spleen, kidney and prostate size, echo pattern, focal lesions and abscess, presence of ascites and lymph node enlargement.

\section{Specific Investigations: (according to the} case)

- Cultures of blood and urine in suspected cases [11].

- Immunological tests as RF, ANA, Anti dsDNA and ASOT [12].

- Widal agglutination test and Brucella agglutination test [13]

- CMV Ab [14].

- EBV Ab [15].

- HIV Ab [16].

- Tuberculin test [17].

- ECHO: With special emphasis on detection of cardiac size, function and presence of vegetations, mass or abscess.

- Computerized tomography (CT), Magnetic Resonant imaging (MRI) and bone marrow biopsy.

\section{Statistical analysis :}

Data collected throughout history, basic clinical examination, laboratory investigations and outcome measures coded, entered and analyzed using Microsoft Excel software. Data were then imported into Statistical Package for the Social Sciences (SPSS version 20.0) (Statistical Package for the Social Sciences) software for analysis. According to the type of data qualitative represent as number and percentage, quantitative continues group represent by mean $\pm \mathrm{SD}$. The following tests were used to test differences for significance; Differences between frequencies (qualitative variables) and percentages in groups were compared by Chi-square test. Differences between parametric quantitative independent groups by $\mathrm{t}$ test. $\mathrm{P}$ value was set at $<0.05$ for significant results $\&<0.001$ for high significant result. 


\section{RESULTS}

Table (1): Fever Pattern of elderly group versus non elderly group

\begin{tabular}{|c|c|c|c|c|}
\hline Parameter & $\begin{array}{c}\text { Group I } \geq \mathbf{6 5} \\
\mathbf{n = 2 7}\end{array}$ & $\begin{array}{c}\text { Group II <65 } \\
\mathbf{n = 2 7}\end{array}$ & \multirow{2}{*}{ Test } & \multirow{2}{*}{ P. Value } \\
\hline Intermittent & $8(29.6 \%)$ & $8(29.6 \%)$ & & \\
\hline Continuous & $14(51.9 \%)$ & $7(25.9 \%)$ & \multirow{2}{*}{8.87} & \multirow{2}{*}{$0.03^{*}$} \\
\hline Remittent & $1(3.7 \%)$ & $9(33.3 \%)$ & & \\
\hline Undulant & $4(14.8 \%)$ & $3(11.1 \%)$ & & 1.00 \\
\hline Association: & $5(18.5 \%)$ & $5(18.5 \%)$ & 0.00 & $0.022^{*}$ \\
\hline Rigor & $1(3.7 \%)$ & $7(25.9 \%)$ & 5.28 & \\
\hline
\end{tabular}

NB: * Significant.

** Highly significant.

Fever in elderly group showed statistically significant increased percentage of the continuous pattern, on the other hand sweating was significantly prominent in non-elderly group.

Table (2) : Laboratory investigation of elderly group versus non elderly group

\begin{tabular}{|c|c|c|c|c|c|}
\hline \multicolumn{2}{|c|}{ Parameter } & $\underset{\substack{\text { Group } I \\
n=27}}{\cos }$ & $\begin{array}{c}\text { Group II }<65 \\
n=27\end{array}$ & Test & $\begin{array}{c}P . \\
\text { Value }\end{array}$ \\
\hline \multicolumn{2}{|c|}{ Total leucocytes count } & $9485.18 \pm 3315$ & $8922.22 \pm 2720$ & 0.534 & 0.595 \\
\hline \multicolumn{2}{|c|}{ Neutrophils } & $68.11 \% \pm 16.4$ & $69.55 \% \pm 14.3$ & -0.344 & 0.732 \\
\hline \multicolumn{2}{|c|}{ Lymphocytes } & $28.66 \% \pm 14.8$ & $28.00 \% \pm 14.3$ & 0.168 & 0.867 \\
\hline \multicolumn{2}{|r|}{$\mathrm{HB}(\mathrm{gm} \%)$} & $10.73 \pm 1.9$ & $10.59 \pm 2.2$ & 0.270 & 0.782 \\
\hline \multicolumn{2}{|c|}{ Platelets $(10)^{3}$} & $174.000 \pm 96.1$ & $234.518 \pm 124.5$ & -1.999 & 0.051 \\
\hline \multirow{2}{*}{ ESR } & 1st hour $\mathrm{mm} / \mathrm{hr}$ & $72.29 \pm 26.5$ & $59.81 \pm 19.4$ & 1.309 & 0.196 \\
\hline & 2nd hour $\mathrm{mm} / \mathrm{hr}$ & $100.18 \pm 38.8$ & $86.22 \pm 26.5$ & 1.359 & 0.180 \\
\hline \multicolumn{2}{|c|}{ CRP mg/dl } & $18.44 \pm 11.0$ & $14.66 \pm 9.6$ & 0.920 & 0.362 \\
\hline \multicolumn{2}{|r|}{ ALT U/L } & $57.66 \pm 37.1$ & $68.85 \pm 60.3$ & -0.820 & 0.416 \\
\hline \multicolumn{2}{|r|}{ AST U/L } & $64.40 \pm 53.6$ & $89.59 \pm 96.4$ & -1.186 & 0.241 \\
\hline \multicolumn{2}{|c|}{ Serum creatinine $\mathrm{mg} / \mathrm{dl}$} & $1.1259 \pm 0.51$ & $0.8889 \pm 0.25$ & 2.159 & $0.035^{*}$ \\
\hline \multicolumn{2}{|c|}{ Serum urea $\mathrm{mg} / \mathrm{dl}$} & $40.22 \pm 26.5$ & $37.74 \pm 31.6$ & 0.321 & 0.756 \\
\hline \multirow{2}{*}{$\begin{array}{c}\text { Urine } \\
\text { analysis }\end{array}$} & Normal & $6(22.2 \%)$ & $11(40.7 \%)$ & \multirow{2}{*}{2.14} & \multirow{2}{*}{0.14} \\
\hline & Abnormal & $21(77.8 \%)$ & $16(59.3 \%)$ & & \\
\hline \multicolumn{2}{|c|}{ Widal test titre $1 / 160$} & $0(0.0 \%)$ & $3(11.1 \%)$ & 3.17 & 0.075 \\
\hline \multicolumn{2}{|c|}{ Brucella test titre $1 / 160$} & $4(14.8 \%)$ & $3(11.1 \%)$ & 0.16 & 0.68 \\
\hline
\end{tabular}

NB: * Significant.

** Highly significant.

Serum creatinine was statistically significant increased in elderly group

Table (3) : FUO categories of elderly group versus non elderly group

\begin{tabular}{|c|c|c|c|c|}
\hline Parameter & Group I $\geq \mathbf{6 5} \mathbf{~ n = 2 7}$ & $\begin{array}{c}\text { Group II <65 } \\
\mathbf{n = 2 7}\end{array}$ & \multirow{2}{*}{ Test } & $\begin{array}{c}\text { P. } \\
\text { Value }\end{array}$ \\
\hline Classic FUO & $23(85.2 \%)$ & $22(81.5 \%)$ & & \\
\cline { 1 - 3 } Nosocomial FUO & $3(11.1 \%)$ & $0(0.0 \%)$ & \multirow{2}{*}{6.3} & \multirow{2}{*}{0.09} \\
\cline { 1 - 3 } Immune deficient FUO & $1(3.7 \%)$ & $2(7.4 \%)$ & & \\
\hline HIV related FUO & $0(0.0 \%)$ & $3(11.1 \%)$ & & \\
\hline Total & $27(100 \%)$ & $27(100 \%)$ & & \\
\cline { 1 - 3 }
\end{tabular}

NB: * Significant.

** Highly significant.

There was no statistical significant difference in FUO categories between both groups. 
Table (4): Causes of FUO in both groups

\begin{tabular}{|c|c|c|c|c|}
\hline Parameter & $\begin{array}{c}\text { Group I } \geq \mathbf{6 5} \\
\mathbf{n = 2 7}\end{array}$ & $\begin{array}{c}\text { Group II <65 } \\
\mathbf{n = 2 7}\end{array}$ & \multirow{2}{*}{ Test } & \multirow{2}{*}{ P. Value } \\
\hline Infectious causes & $15(55.5 \%)$ & $18(66.6 \%)$ & & \\
\hline Auto immune causes & $0(0.0 \%)$ & $3(11.1 \%)$ & & \multirow{2}{*}{6.8} \\
\hline Malignant causes & $3(11.2 \%)$ & $2(7.4 \%)$ & \multirow{2}{*}{0.14} \\
\hline Miscellaneous causes & $3(11.1 \%)$ & $0(0.0 \%)$ & & \\
\hline Undiagnosed causes & $6(22.2 \%)$ & $4(14.8 \%)$ & & \\
\hline Total & $27(100 \%)$ & $27(100 \%)$ & & \\
\hline
\end{tabular}

NB: * Significant.

** Highly significant.

There was no statistical significant difference in causes of FUO between both groups.

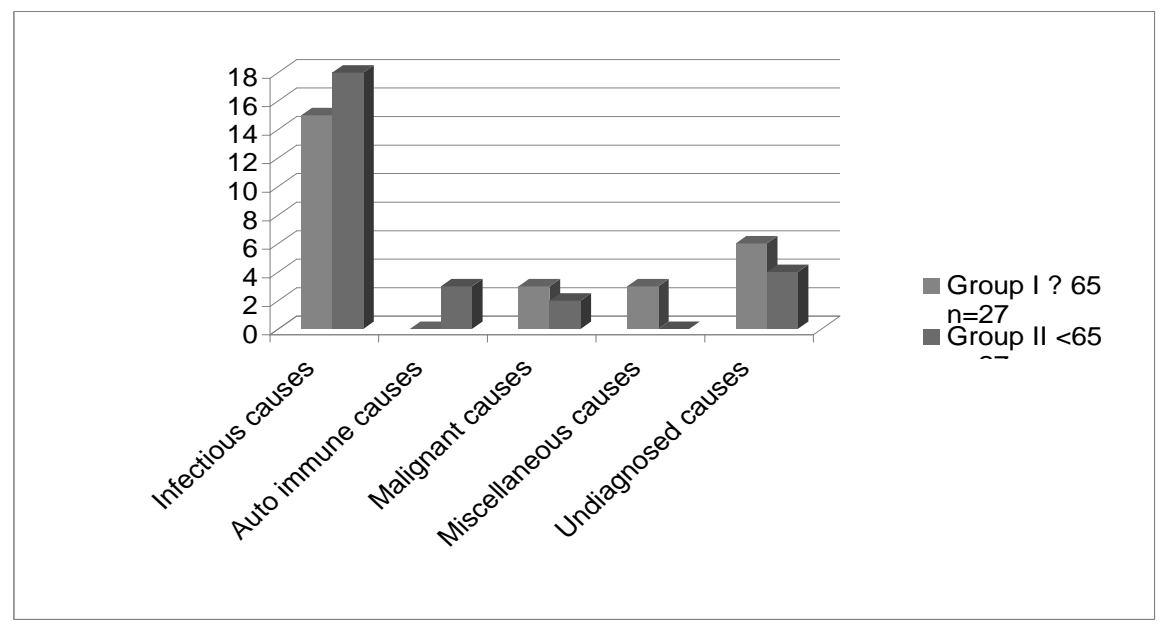

Figure (1): Causes of FUO in both groups

Table (5) : Infectious causes of FUO in both groups

\begin{tabular}{|c|c|c|c|c|}
\hline Parameter & $\begin{array}{c}\text { Group I } \geq \mathbf{6 5} \\
\mathbf{n = 1 5}\end{array}$ & $\begin{array}{c}\text { Group II }<\mathbf{6 5} \\
\mathbf{n = 1 8}\end{array}$ & $\mathbf{X}^{\mathbf{2}}$ & P. Value \\
\hline UTI & $7(46.7 \%)$ & $1(5.5 \%)$ & 32.2 & $0.00^{* *}$ \\
\hline Brucellosis & $4(26.7 \%)$ & $3(16.7 \%)$ & 2.3 & 0.12 \\
\hline chronic calcular cholecystitis & $2(13.3 \%)$ & $0(0.0 \%)$ & 11.07 & $0.0003^{* *}$ \\
\hline Typhoid fever & $0(0.0 \%)$ & $3(16.7 \%)$ & 14.7 & $0.0001^{* *}$ \\
\hline CMV & $0(0.0 \%)$ & $1(5.5 \%)$ & 3.6 & 0.055 \\
\hline EBV & $0(0.0 \%)$ & $1(5.5 \%)$ & 3.6 & 0.055 \\
\hline HIV & $0(0.0 \%)$ & $3(16.7 \%)$ & 14.7 & $0.0001^{* *}$ \\
\hline Malaria & $0(0.0 \%)$ & $1(5.5 \%)$ & 3.6 & 0.055 \\
\hline Infective endocarditis & $0(0.0 \%)$ & $2(11.1 \%)$ & 9.1 & $0.002^{*}$ \\
\hline Intra-abdominal abscess & $0(0.0 \%)$ & $2(11.1 \%)$ & 9.1 & $0.002^{*}$ \\
\hline T.B & $2(13.3 \%)$ & $1(5.5 \%)$ & 3.23 & 0.07 \\
\hline Infectious causes & $\mathbf{1 5}(\mathbf{1 0 0 \% )}$ & $\mathbf{1 8}(\mathbf{1 0 0 \% )}$ & & \\
\hline
\end{tabular}

NB: * Significant. ** Highly significant.

Elderly group showed statistical significant increase in urinary tract infection (UTI) and chronic calcular cholecystitis, while non-elderly group showed statistical significant increase in typhoid fever, HIV infection, infective endocarditis and intra-abdominal abscess when compared to elderly group. 


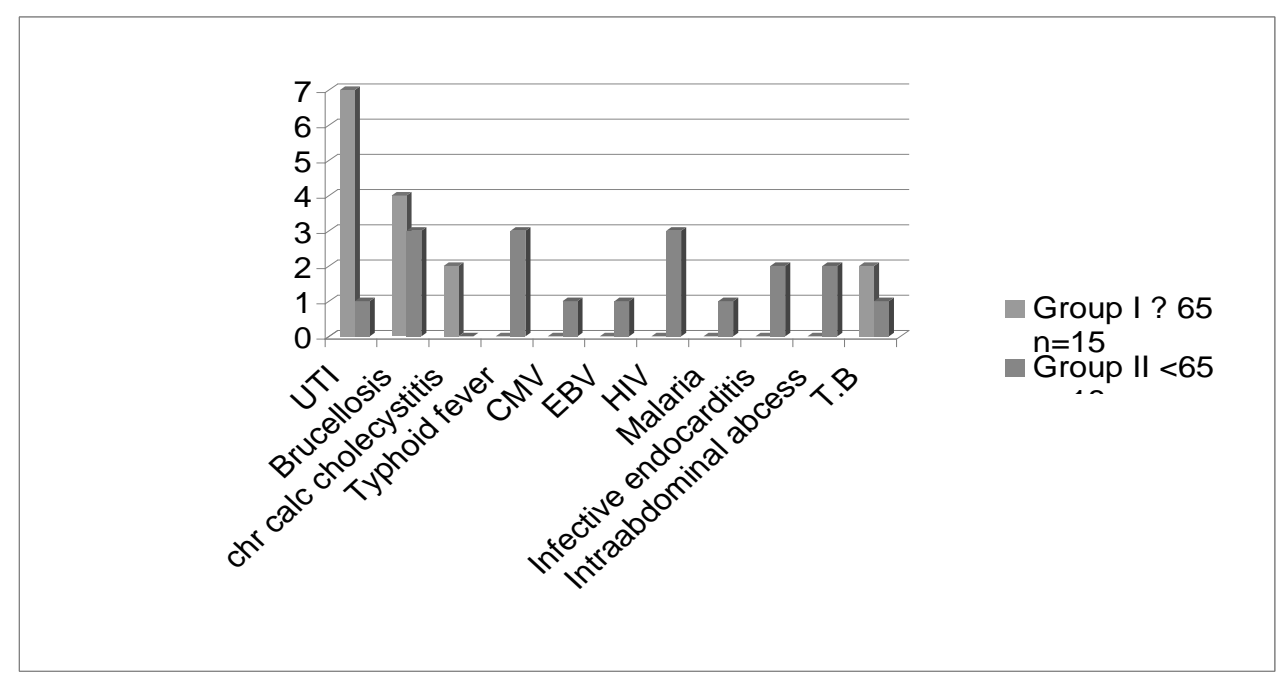

Figure (2): infectious causes of FUO in both groups

Table (6): Non infectious causes of FUO in both groups

\begin{tabular}{|c|c|c|c|c|}
\hline Parameter & $\begin{array}{c}\text { Group I } \geq \mathbf{6 5} \\
\mathbf{n = 6}\end{array}$ & $\begin{array}{c}\text { Group II }<\mathbf{6 5} \\
\mathbf{n = 5}\end{array}$ & Test & P. Value \\
\hline Auto immune thyroiditis & $0(0.0 \%)$ & $1(20 \%)$ & 18.05 & $0.00^{* *}$ \\
\hline SLE & $0(0.0 \%)$ & $2(40 \%)$ & 38.02 & $0.00^{* *}$ \\
\hline HCC & $2(33.2 \%)$ & $0(0.0 \%)$ & 31.2 & $0.00^{* *}$ \\
\hline Bone marrow carcinoma & $1(16.7 \%)$ & $2(40 \%)$ & 9.5 & $0.001^{* *}$ \\
\hline Post chemotherapy & $1(16.7 \%)$ & $0(0.0 \%)$ & 14.7 & $0.0001^{* *}$ \\
\hline Drug fever & $1(16.7 \%)$ & $0(0.0 \%)$ & 14.7 & $0.0001^{* *}$ \\
\hline Septic shock \&multi organ failure & $1(16.7 \%)$ & $0(0.0 \%)$ & 14.7 & $0.0001^{* *}$ \\
\hline Total & $6(100)$ & $5(100)$ & ---- & ----- \\
\hline
\end{tabular}

NB: * Significant. ** Highly significant.

Elderly group showed statistical significant increase in hepatocellular carcinoma, post chemotherapy, drug fever and septicemia while non-elderly group showed statistical significant increase in auto immune disorder when compared to elderly group.

\section{DISCUSSION}

Fever of undetermined origin constitutes one of the greatest challenges of clinical practice; it has been categorized into four categories: classic, nosocomial, Immune deficient and HIV associated FUO [3]. The diagnostics of FUO in the elderly often differs from the young patients, the manifestation of a disease is often non specific in older patients, physiologic reserves are diminished in the elderly as well as their immunity [5].

This study was conducted to determine causes, clinical presentations and the laboratory findings of FUO among elderly persons $\geq 65$ years in comparison with younger patients and define the most common causes responsible for FUO in elderly.

In this study continuous fever pattern formed $51.9 \%$ of cases in elderly group $\geq 65$ and $25.9 \%$ of cases in group $<65$. The higher incidence of continuous pattern in elderly group $\geq 65$ is due to the increase of UTI in this group. It was reported by John Marx [18] that, UTI is accompanied with continuous fever pattern. Sweating was less prominent in elderly group $\geq 65$ due to disturbance of autonomic nervous system by chronic illness as diabetic neuropathy, uremia and excessive drugs intake [19].

In this study serum creatinine showed statistically significant increase in elderly group, although it was still in the normal range. It may remain within the reference range despite marked renal impairment in patients with low muscle mass, so the sensitivity of serum creatinine for the early detection of kidney disease is poor [20].

In the present study, there was no statistical significant difference in FUO categories (classic, 
nosocomial, Immune deficient and FUO associated with HIV infection) between both groups.

In this study $55.5 \%$ of cases in elderly group were due to infection versus $66.6 \%$ of cases in the other group. $11.1 \%$ of cases were in group $<65$ due to auto immune causes. In the elderly group malignant causes represent $11.2 \%$ of cases versus $7.4 \%$ of cases in group $<65$. Miscellaneous causes as post chemotherapy, drug fever and septicemia represent $11.1 \%$ in elderly group $\geq 65$ and not present in group $<65$ and undiagnosed causes were $22.2 \%$ in elderly group $\geq 65$ while $14.8 \%$ in group $<65$. Ankunda et al. [22] reported that high incidence of HIV in young adults due to sexual activity and IV drug abuse

In studied infectious causes; elderly group showed statistical significant increase in urinary tract infection. The higher incidence of UTI in in group $\geq 65$ was due to risk factors including uncontrolled diabetes, stones, urinary catheter, increase size of prostate and uterine prolapse [21]. The non-elderly group showed statistical significant increase in typhoid fever, HIV infection, infective endocarditis and intra-abdominal abscess. Ankunda et al. [22] reported that high incidence of HIV in young adults due to sexual activity and IV drug abuse. Infective endocarditis was due to rheumatic cardiac valvular lesions.

This study agreed with previous studies where infections are the commonest cause of FUO. Ammari [23] and MIR et al. [24] mentioned that infections were ranged from $41.3 \%$ to $53 \%$ of cause of FUO. On the other hand the current results disagreed with the results of studies of Knockaert et al. [25] and Naito et al. [26] who reported that infections to be responsible for $25.5 \%$ and $23.1 \%$, of cases of FUO. This may be due to difference in geographical distribution of infectious diseases.

In this studied groups, $11.1 \%$ of cases were due to auto immune causes that were prominent in group $<65$ and not present in elderly group $\geq 65$, where SLE formed $40 \%$ of noninfectious causes while auto immune thyroiditis formed $20 \%$ of noninfectious causes. This agreed with MIR et al. [24] and Ammari [23] who reported auto immune causes to be responsible for $12 \%$ of cases of FUO. However disagreed with Stamatis et al. [27] and Naito et al. [26] who reported auto immune causes to be responsible for $33 \%$ and $30.6 \%$ of cases of FUO. This may be explained by genetic difference and exposure for provocative factors.
In this study $11.2 \%$ of cases were due to malignant causes in elderly group $\geq 65$, while $7.4 \%$ of cases were due to malignant causes in group $<65$, where hepatocellular carcinoma formed $33.3 \%$ of noninfectious causes in elderly group $\geq 65$. Bone marrow carcinoma formed $16.7 \%$ of noninfectious causes in elderly group $\geq 65$ and $40 \%$ of noninfectious causes in group $<65$.

The high incidence of hepatocellular carcinoma in our study because there is number of patients had chronic hepatitis $\mathrm{C}$ virus infection which predispose to hepatocellular carcinoma. This study agreed with Knockaert et al. [25] and Hu et al. [28] who reported malignant causes to be responsible for $12 \%$ and $12.7 \%$ of cases of FUO. However disagreed with Esposito and Gleckman [29] and Ali-Eldin et al. [30] who reported malignant causes to be responsible for $23.4 \%$ and $30.1 \%$ of cases of FUO.

In current study miscellaneous causes as post chemotherapy, drug fever and septicemia represent $11.1 \%$ in elderly group $\geq 65$ and not present in group <65. This agreed with Knockaert et al. [25] and Naito et al. [26] who reported miscellaneous causes to be responsible for $10.6 \%$ and $12.4 \%$ of cases of FUO. However disagreed with MIR et al. [24], Kejariwal et al. [31] and Ammari [23] who reported miscellaneous causes to be responsible for $4.3 \%, 5 \%$ and $23 \%$ of cases of FUO. This discrepancy may be due to different study population.

In our study, undiagnosed causes were $22.2 \%$ in elderly group $\geq 65$ versus $14.8 \%$ in group $<65$. This agreed with Ali-Eldin et al. [30], Hu et al. [28] Kejariwal et al. [31] who reported undiagnosed causes to be responsible for $12.9 \%, 14.1 \%$ and $14 \%$ of cases of FUO in group <65. Also agreed with Naito et al. [26] MIR et al. [24] and Stamatis et al. [27] who reported undiagnosed causes to be responsible for $23.1 \%, 23 \%$ and $20.5 \%$ of cases of FUO in elderly group $\geq 65$.

\section{CONCLUSION}

We concluded that, Urinary tract infection, chronic calcular cholecystitis, malignant causes (including hepatocellular carcinoma) and miscellaneous causes (as post chemotherapy, drug fever and septicemia) are important causes for FUO in elderly patients. Non-elderly group showed statistical significant increase in auto immune disorders when compared to elderly group. Also we found that categories 
of FUO (classic, nosocomial, Immune deficient, and FUO associated with HIV infection) in elderly patients did not differ from non-elderly patients.

Limitation of the study: Further studies with larger sample size are needed to obtain more accurate statistical analysis of the causal categories or studying of the individual causal categories alone.

Funding: None.

Conflicts of interest: None.

Ethical Approval:Approved

\section{REFERENCES}

1- Petersdorf RG and Beeson PB. Fever of unexplained origin: report on 100 cases. Medicine; 1961, 40:1-30.

2- Arnow PM. Fever of unknown origin. Review article. Lancet; 1997, 350: 575-580.

3- Durack DT and Street AC. Fever of unknown origin reexamined and redefined. Curr Clin Top Infect Dis; 1991, 11:35-51.

4- Norman DC. Fever in the elderly, Oxford Journals Medicine \& Health Clinical Infectious Diseases 2000, Volume; 31 : 148-151.

5- Mackowiak AP and Durack DT. Fever of unknown origin. In: Mandell GL, Bennett JE, Dolin R. Principles and Practice of Infectious Diseases. 6th ed. Philadelphia: Churchill Livingstone; 2005, p.718-729.

6- Simerville JA, Maxted WC and Pahira. Urinalysis: A comprehensive review. American Family Physician; 2005, 71: 1153 -1162.

7- Hoffman R, Benz EJ and Shittil. Haematology: Basic principles and practice. Churchill Livingstone Inc., USA: 1991, 1-120 WF.

8- Balistreri WF and shaw LM. Biochemical assessment of liver function. In Tietz $\mathrm{N}$ (edn) Textbook of clinical chemistry, W.B. Saunders Company, Philadelphia; 1986, 1373-1433.

9- Rock RC, Walker WG and Jenning D. Tests of renal functions .In Tietz (edn) textbook of clinical chemistry. W.B. Saunders Company, Philadelphia; 1986, 1262 - 1287.

10- Liu S, Ren J, Xia Q and Wu X. Preliminary casecontrol study to evaluate diagnostic values of Creactive protein and erythrocyte sedimentation rate in differentiating active Crohn's disease from intestinal lymphoma, intestinal tuberculosis and Behcet's syndrome. The American Journal of the Medical Sciences; 2013, 346: 467-472.

11- Dean AJ and Lee DC. Beside laboratory and microbiologic procedures. In Roberts JR, Hedges JR,eds .Clinical procedures in Emergency Medicine. 5th ed. Phildelphia. Saunders Elsevier; 2009, 68: $1360-1365$.

12- Lane J. Clinical utility of common serum rheumatologic tests. Am Fam Physician; 2000, 65: $1073-1080$.
13- Willke A, Ergonul O and Bayer B. Widal test in diagnosis of typhoid fever in Turkey. Clinical and Diagnostic Laboratory Immunology; 2002, 938: 941.

14- Revello MG and Gerna G. Diagnosis and management of human cytomegalovirus infection. Clin. Microbiol. Rev; 2002, 15:680-715.

15- Ebell MH. Epstein-Barr virus infectious mononucleosis. American Family Physician; 2004, 70:1279-1287.

16- Chou R, Huffman LH, Fu R, Smits AK and Korthuis PT. Screening for HIV: a review of the evidence for the U.S. Preventive Services Task Force. Annals of Internal Medicine; 2005, 143: 55-73.

17- James E, Frederick L. Ruben, and A. Michael Bloh. Immediate Hypersensitivity Reactions after Use of Tuberculin Skin Testing. Clinical Infectious Diseases; 2002, 34:12-13.

18- John Marx. Rosen's emergency medicine: concepts and clinical practice. Mosby/Elsevier. 2006, P: 2239.

19- Murota H. Sweating in Systemic Abnormalities: Uremia and Diabetes Mellitus. Current Problems in Dermatology; 2016, 51:57-61.

20- Lamb EJ, O'Riordan SE and Delaney MP. Kidney functions in older people: pathology, assessment and management. International Journal of Clinical Chemistry; 2003, 334: 25-40.

21- Dielubanza, EJ and Schaeffer AJ. Urinary tract infections in women. The Medical Clinics of North America; 2011, 95: 27-41.

22- Ankunda R, Atuyambe LM and Kiwanuka N. Sexual risk related behaviour among youth living with HIV in central Uganda: implications for HIV prevention. Research Department, Ernest Cook Ultrasound Research and Education Institute, Mengo Hospital, Kampala, Uganda; 2016, 11;24:49.

23- Ammari F. Fever of unknown origin in North Jordan. Trop Doct.; 2006, 36:251-253.

24- MIR T, Nabi Dhobi G, Nabi Koul A, and Saleh T. Clinical profile of classical Fever of unknown origin: Caspian Journal of Internal Medicine; 2014, 5: 35-39.

25- Knockaert DC, Vanneste LJ and Bobbaers HJ. Fever of unknown origin in the elderly patients. $J$ Am Geriatr Soc; 1993, 41:1187-1192.

26- Naito T, Torikai K, Mizooka M, Mitsumoto F, Kanazawa K, Ohno S, Morita H, Ukimura A, Mishima N, Otsuka F, Ohyama Y, Nara N, Murakami K, Mashiba K, Akazawa K, Yamamoto K, Tanei M, Yamanouchi M, Senda S, Tazuma S and Hayashi J. Diagnostic workup for fever of unknown origin: a multicenter collaborative retrospective study. British Medical Journal Open; 2013, 3: e 003971.

27- Stamatis P, Pefanis AV, Tsiakou AG and Skeva II. Fever of unknown origin: Discrimination between infectious and non-infectious causes. 
Third University Department of Medicine, Sotiria Hospital, Athens, Greece Received 31 July 2009, Revised 31 October 2009, Accepted 15 November 2009, Available online 6 December 2009.

28- Hu Y1, Lu H, Zhang Yand Jiang W. Fever of unknown origin: revisit of 142 cases in a tertiary Chinese hospital, Department of Infectious Diseases, Huashan Hospital Affiliated to Fudan University, Shanghai, China; 2008, 2:44-446.

29- Esposito AL and Gleckman RA. Fever of unknown origin in the elderly. J Am Geriatr Soc; 1978, 26:498-505.
30- Ali-Eldin FA, Abdelhakam SM and Ali-Eldin ZA. Clinical spectrum of fever of unknown origin among adult Egyptian patients admitted to Ain Shams University Hospitals: a hospital based study, Department of Tropical Medicine, Faculty of Medicine, Ain Shams University, Cairo, 2011, 11566, Egypt:379-386.

31- Kejariwal D, Sarkar N, Chakraborti S K and Agarwal V. Pyrexia of unknown origin: a prospective study of 100 cases. J Postgrad Med; 2001, 47:104. 